COMMENTARY ON COVID-19 AND THE FoOd SYSTEM

\title{
Google searches reveal changing consumer food sourcing in the COVID-19 pandemic
}

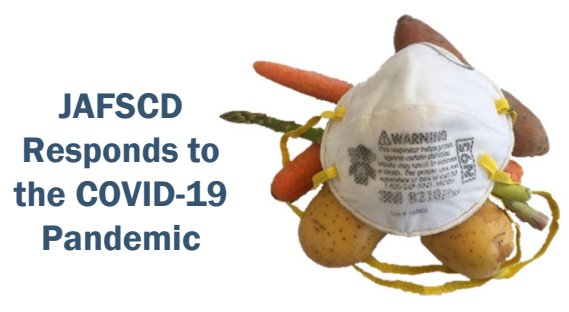

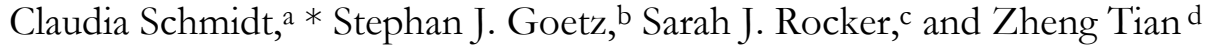 \\ Pennsylvania State University
}

Submitted April 30, 2020 / Published online May 21, 2020

Citation: Schmidt, C., Goetz, S. J., Rocker, S. J., \& Tian, Z. (2020). Google searches reveal changing consumer food sourcing in the COVID-19 pandemic. Journal of Agriculture, Food

Systems, and Community Development, 9(3), 9-16. https://doi.org/10.5304/jafscd.2020.093.032

Copyright (C) 2020 by the Authors. Published by the Lyson Center for Civic Agriculture and Food Systems. Open access under CC-BY license.

\section{Introduction}

Consumers are dramatically changing their food purchasing habits in response to the evolving COVID19 pandemic (Kolodinsky, Sitaker, Chase, Smith, \& Wang, 2020; Schmidt et al., 2020; Worstell, 2020). In part this is due to growing public awareness that food supply chains, which normally operate largely unnoticed and with great efficiency, are in fact fragile and vulnerable. With supply chain interruptions and mandates in several states for social distancing and a reduced number of grocery shop trips, consumers are compelled to think about food storability as well different food sourcing options. In this commentary we examine how consumer interest has changed since the advent of the pandemic, by observing Google search trends. Google Trends analysis has been widely used to study health-related aspects of COVID-19 and earlier pandemics (Arora, McKee, \& Stuckler, 2019; Carneiro \& Mylonakis, 2009; Ginsberg et al., 2009; Mavragani \& Ochoa, 2019; Mavragani, Ochoa, \& Tsagarakis, 2018; Nuti et al., 2014), but to our knowledge not to track changing consumer behavior with respect to food sourcing

\footnotetext{
a * Corresponding author: Claudia Schmidt, Department of Agricultural Economics, Rural Sociology and Extension Education, Pennsylvania State University; 207-D Armsby, University Park, PA 16802-5602 USA; cschmidt@psu.edu

b Stephan J. Goetz, Northeast Regional Center for Rural Development, Department of Agricultural Economics, Rural Sociology and Extension Education, Pennsylvania State University; 207-C Armsby, University Park, PA 16802-5602 USA; sgoetz@psu.edu

c Sarah J. Rocker, Northeast Regional Center for Rural Development, Department of Agricultural Economics, Rural Sociology and Extension Education, Pennsylvania State University; 207-B Armsby, University Park, PA 16802-5602 USA.

d Zheng Tian, Northeast Regional Center for Rural Development, Department of Agricultural Economics, Rural Sociology and Extension Education, Pennsylvania State University; 007-B Armsby, University Park, PA 16802-5602 USA; zzt36@psu.edu
} 
in real time. ${ }^{1}$ We offer these comments both as potential real-time tracking of consumer preferences, as well as working hypotheses for future more vigorous investigations.

Google Trends ${ }^{2}$ data can reveal not only what is preoccupying the public at a point in time, but also how that compares with preoccupations over the course of a year (i.e., year-to-year comparisons), as well as to other topics. ${ }^{3}$ In the case of the pandemic, Washington state was the first to declare a COVID-19related emergency, on February 29, 2020, while California was the first to issue a stay-at-home order, on March 19, after having declared an emergency on March 4 (Kelleher, 2020; Mervosh, Lu, \& Swales, 2020). In terms of national consumer interest or preoccupations, we are able to observe three fairly distinct periods in terms of food-related searches. First, a concern with food storage, starting the week of February 16-22 and continuing until mid-April, coupled with some evidence about concerns over food shortages (starting March 1-7). Second, starting the week of March 1-7, a growing interest in more local, direct options for acquiring food emerged, which continues to this day. Third, starting the week of March 8-14 and spiking a few weeks later (except for Grubhub), growing interest in take-out food and home delivery, as the stay-at-home orders became more widespread. This was also the week in which searches for food banks and pantries started to take off, just preceding the week of March 22, which saw record increases in initial jobless claims (3.3 million) (Trading Economics, n.d.).

\section{Week of February 16-22: Consumers are concerned about storing food (and potentially hoarding).} With the looming pandemic, consumers became increasingly interested in storable basic food items, whether that food was fresh, canned, frozen, refrigerated, or dried (Figure 1). These searches started to rise during the week of February 16-22 in the cases of dried food and canned food, a period that also coincided with anecdotal evidence of empty shelves for certain food items, including beans, flour, and pasta. Searches on fresh food were gradually rising even earlier but jumped March 8-14, while in the case of frozen food the increase occurred the week of March 1-7. Interest in frozen food was also the last to spike, during April 5-11.

\section{Figure 1. Interest Over Time: Food by Storage-Related Processing (last 12 months)*}

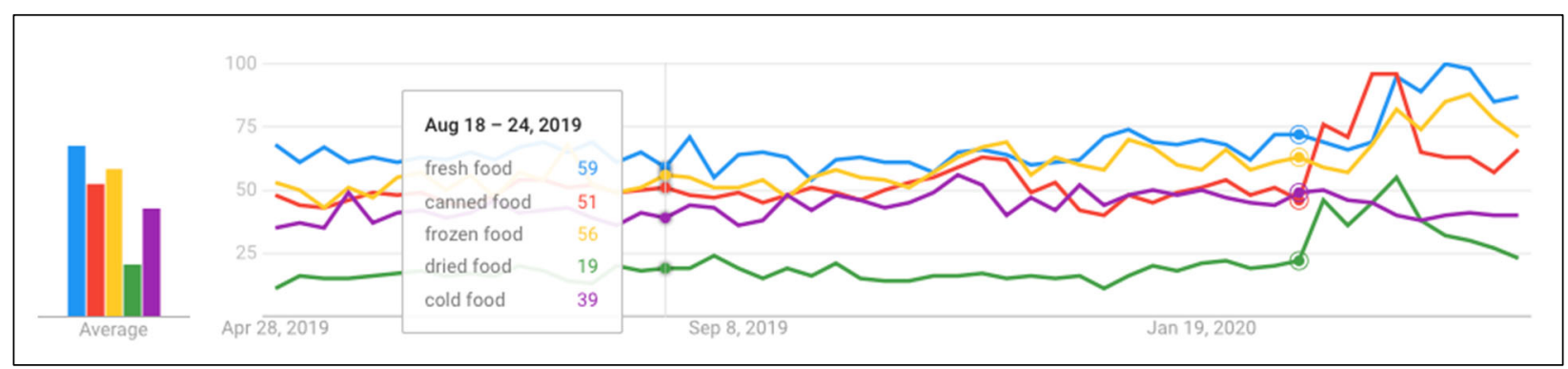

Source: Google Trends, April 27, 2020; the geography of search is the U.S.; circles to the right show week of Feb. 16-22, 2020.

* Note for this and the other figures: We capture Google search results directly as screenshots. In order to keep the graphs small while adding a legend, we use the feature whereby hovering the cursor over the lines on a certain data also provides a legend for the lines; this date is reported but arbitrary for present purposes. The dates that are relevant are shown as dots with circles and are closer to the right sides of the graphs.

\footnotetext{
1 These searches are not without potential problems; for a summary discussion see: https://medium.com/@pewresearch/using-google-trends-data-for-research-here-are-6-questions-to-ask-a 7097f5fb526

2 "Numbers represent search interest relative to the highest point on the chart for the given region and time. A value of 100 is the peak popularity for the term. A value of 50 means that the term is half as popular. A score of 0 means there was not enough data for this term" (https://google.com)

${ }^{3}$ Except where noted, the search is for the entire U.S. and for the last 12 months.
} 
In terms of the distribution across states (Figure 1a), searches for fresh food tended to dominate in the eastern half of the U.S., except in West Virginia and Vermont, where canned food dominated, while frozen food was of greatest interest in Northern New England, Connecticut, and Ohio and selected and intermountain west states as well as Iowa. Canned food searches showed a similarly dispersed pattern, with Washington, Oregon, Montana, and a few other states standing out.

\section{Figure 1a. Distribution of Prominent Search Terms by State}

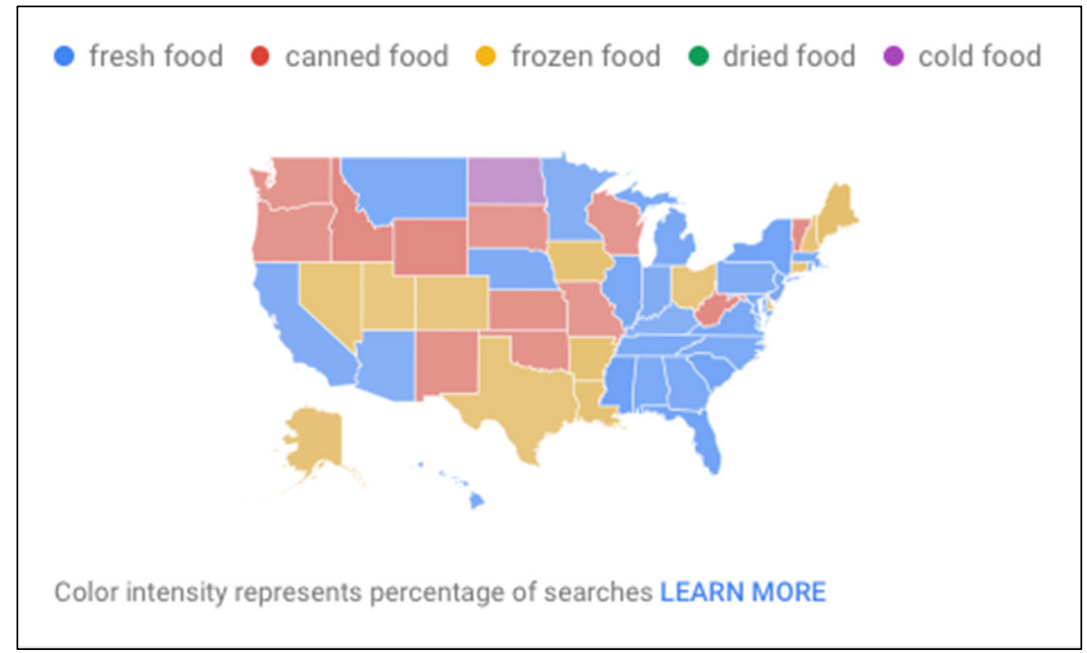

Source: Google Trends, April 27, 2020.

The notion that consumers were thinking about food shortages is confirmed by searches on this term, which dominated the individual food categories (Figure 1b) and remains high as of this paper's writing at $50 \%$ after spiking early on. The states of North Dakota, New Mexico, Montana, Idaho, and Utah dominated in search interest over this period.

Figure 1b. Search Interest for Food Shortage Coincides with Beginning of Pandemic (12 months)

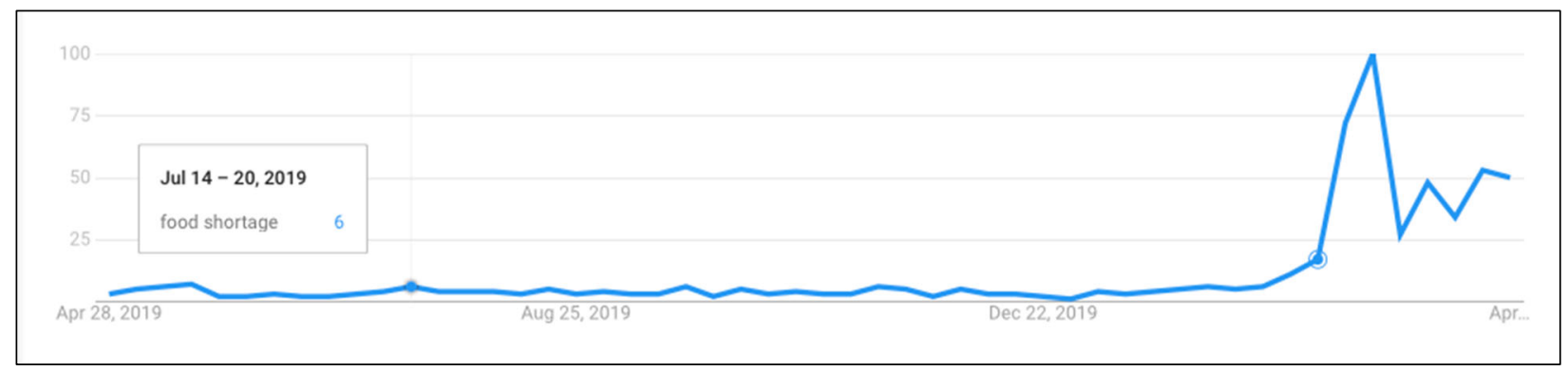

Source: Google Trends, April 27, 2020; the geography of search is the U.S.; circles to the right show week of March 1-7, 2020.

To put this one-year search pattern in perspective, Figure 1c shows the data since 2004. Subject to the caveat that the collection method and search function have changed over time, this figure suggests a slightly greater concern about or preoccupation with food availability in the current pandemic than was true in April 2008, the previous peak period of global food scarcity that was due to production shortfalls around the world (over the overall period for which data are available). 
Figure 1c. The Long View of Search Interest in Food Shortage (2004-2020)

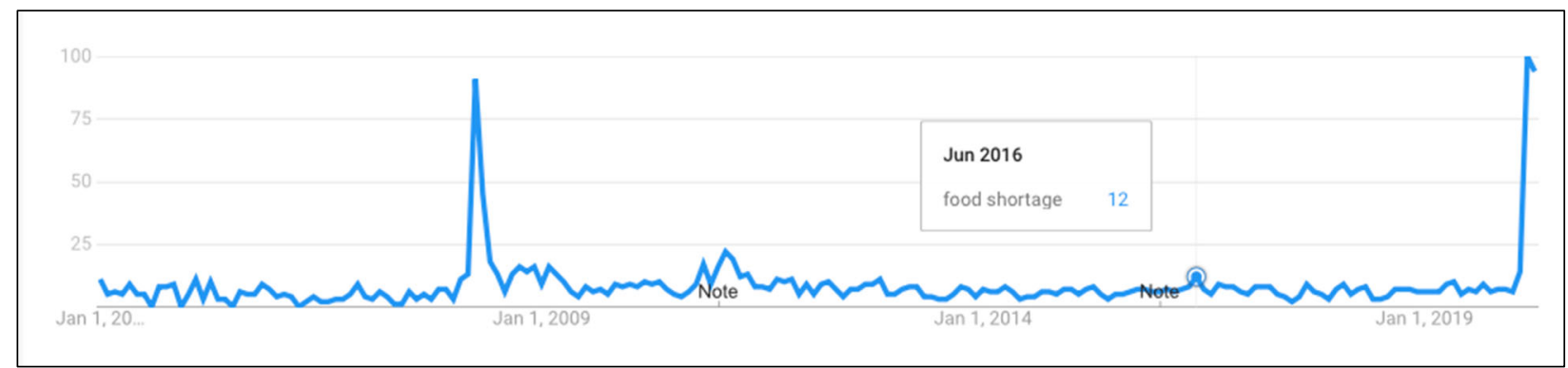

Source: Google Trends, April 27, 2020; the geography of search is the U.S.; The "note" labels mark when Google Trends made a change in the collection method.

\section{Week of March 1-7: Consumers start to think about local options for sourcing food.}

Along with the concern about the storability of different foods, consumers also started to look for other, more local sources of food around the first week of March. For community supported agricultural operations (CSAs), the searches had already been gradually rising since the beginning of the year as consumers sought to connect with farmers who were making early planning decisions for what to grow, reflecting normal season search patterns. Interest in CSAs were the highest in Vermont, the District of Columbia, Massachusetts, and Oregon. The terms local farm and food also enjoyed moderate search interest in this period. Searches for these terms have only recently peaked, and they continue to rise in the case of searches for produce box — mostly in North Carolina_-as the harvest season accelerates.

\section{Figure 2. Interest Over Time: Switching to More Local Direct Options}

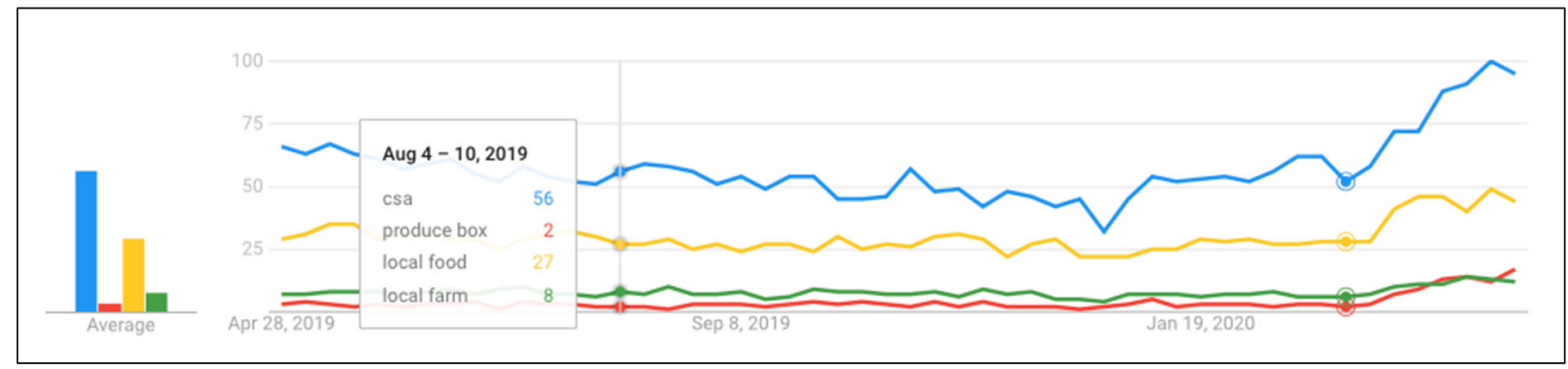

Source: Google Trends, April 27, 2020; circles to the right show week of March 1-7, 2020.

3. Week of March 8-14: With growing fears about the virus and shutdown orders, consumers look to takeout and delivery options.

About a week later, as consumers could no longer go to restaurants and with social distancing and shutdown orders in place, they turned to yet another food access option, with the terms takeout, Grubbub and food delivery each experiencing surging interest during the week of March 8-14. In these searches, food delivery could be from grocery stores as well as restaurants.

The terms Uber Eats; Peapod and Instacart show similar trends (with the latter having twice the search volume of takeout). It is also noteworthy that Grubhub is enjoying sustained interest even as the other terms are falling off in terms of interest. North and South Dakota and Delaware dominated in food delivery searches, while Grubbub was most prominent in Oregon, Utah, and Illinois. 
Figure 3a. Switching to Options Outside Restaurants (and Stores)

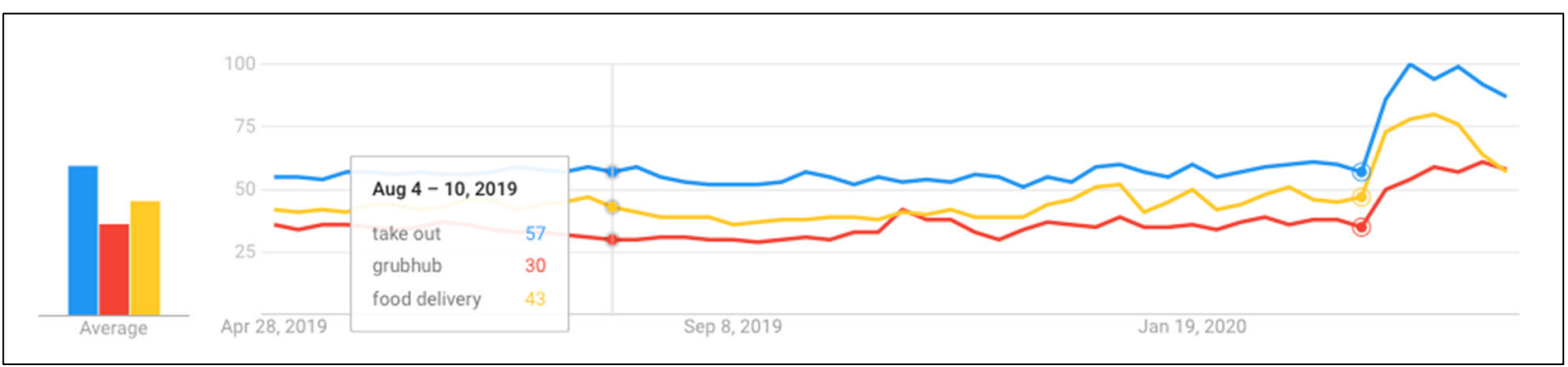

Source: Google Trends, April 27, 2020; circles to the right show week of March 8-14, 2020.

During March 8-14, as the first waves of layoffs started to occur, searches for emergency food aid also started to rise. The term food bank dominated in Washington, Montana, Arizona and Idaho. In some states, including Washington, the National Guard has been called in to support food bank operations, which are experiencing higher-than-ever client demand on top of shortages of food supply and workers (Kulish, 2020). For food pantry, Wisconsin, Illinois, South Dakota, North Dakota, and Missouri dominated.

Figure 3b. Rising Demand for Food Aid

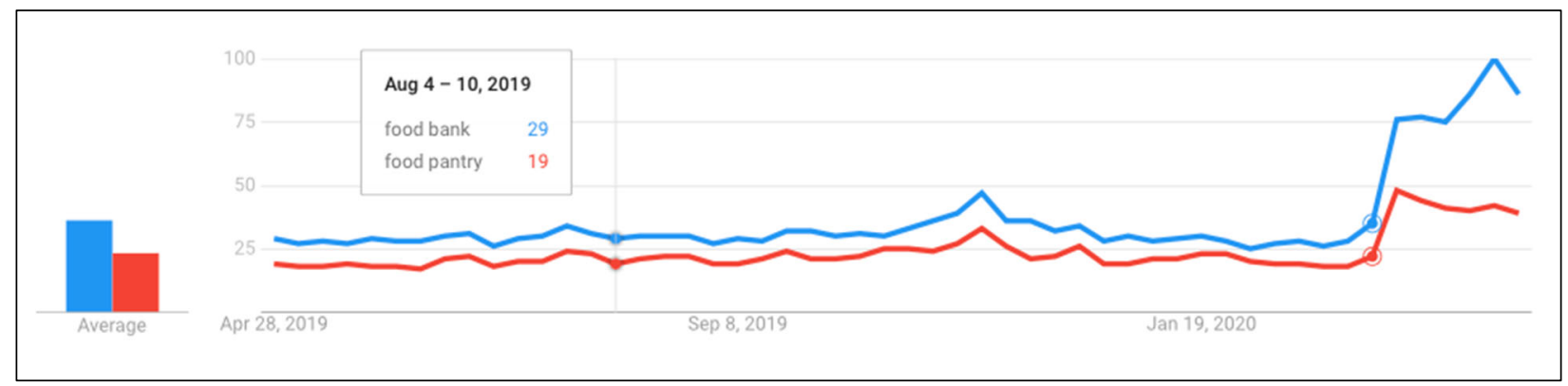

Source: Google Trends, April 27, 2020; circles to the right show week of March 8-14, 2020.

\section{The broader, changing context of where food is sourced.}

To place the above findings in context, we show search trends for grocery stores, farmers markets, and food banks over the course of the last 12 months (Figure 4). Even though consumers normally start to think about local options for sourcing food in the early spring, farmers market searches are lower (by about half) this year over the previous year, most likely because of social distancing concerns as well as orders prohibiting farmers market operations as non-essential in some states. Based on the patterns last spring (and earlier years - not shown), seasonal searches for farmers markets should be increasing at this time as consumers start to expect early spring harvests at least in some parts of the country. But this year, even as some farmers markets adapt (Schmidt et al., 2020) by using curbside delivery, etc., the searches remain low.

Grocery store searches are well above seasonal search patterns normally observed this time of the year, spiking noticeably on March 15, and slightly greater than searches around the end of year holidays of Thanksgiving and Christmas. This is likely because consumers are verifying store hours of operation (including special hours for senior citizens) or perhaps planning grocery trips in order to stock up on food. The latter would explain why the search intensity has declined recently to a level more similar to that of last year at this time. 
As already noted, interest in information on food banks has increased sharply since the beginning of March in a relative sense. Normally such search demand rises only in the few weeks before Thanksgiving, but during the pandemic the volume is two to three times higher.

Figure 4. The Broader Context: Farmers Markets, Grocery Stores, and Food Banks
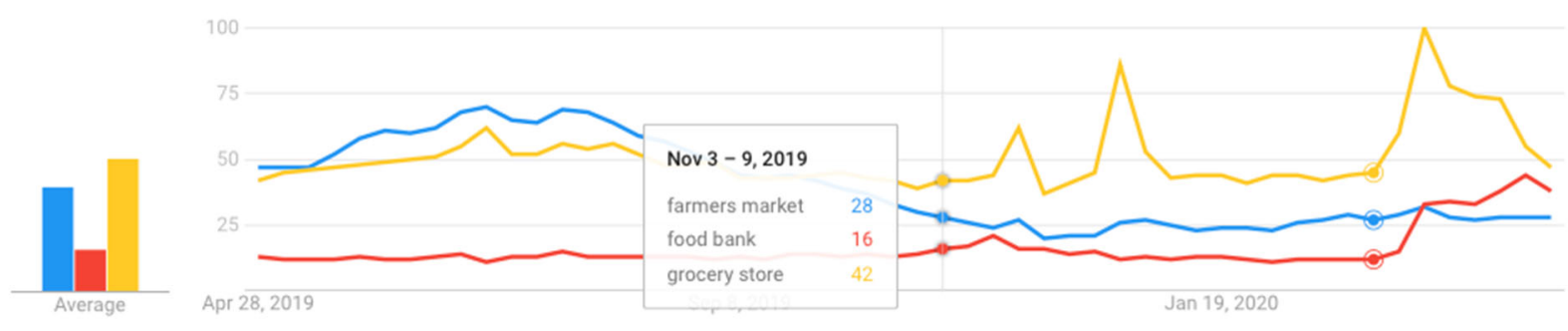

Source: Google Trends, April 27, 2020; the geography of search is the U.S.; circles to the right show week of March 1-7, 2020.

\section{Despite growing interest in local, demand for breweries and wineries has dramatically dropped.}

As a result of stay-at-home rules and social distancing relatively early in the pandemic, consumers ceased to look up much information on breweries and wineries, starting in mid-February (Figure 5a). However, although at a considerably smaller search volume, interest in distilleries has risen in recent weeks, perhaps as consumers sought more potent forms of alcohol, as liqour stores shut their doors in some states under non-essential business closures, or as they were looking for local sources of hand sanitizer (Distilled Spirits Council, n.d.). Searches for breweries and wineries, which tend to provide experiences rather than mere commodities, is greatest during the summer and again around the late-year holidays, and normally search volumes should be rising at this time rather than falling (Figure 5a). Both of these search terms are overshadowed by searches for liquor stores (Figure 5b), perhaps reinforcing the idea that consumers are seeking a greater variety and perhaps more potent drinks. ${ }^{4} \mathrm{~A}$ concern raised in Pennsylvania after liquor stores were closed was that sudden withdrawal could be life threatening for alcoholics (Whelan, 2020); Pennsylvania residents also started to drive into adjacent states to purchase liquor, contributing to concerns that they would be bringing the virus with them to these locations (Ebrahimji, 2020).

\section{Figure 5a. Search Intensity for Breweries, Wineries, and Distilleries}

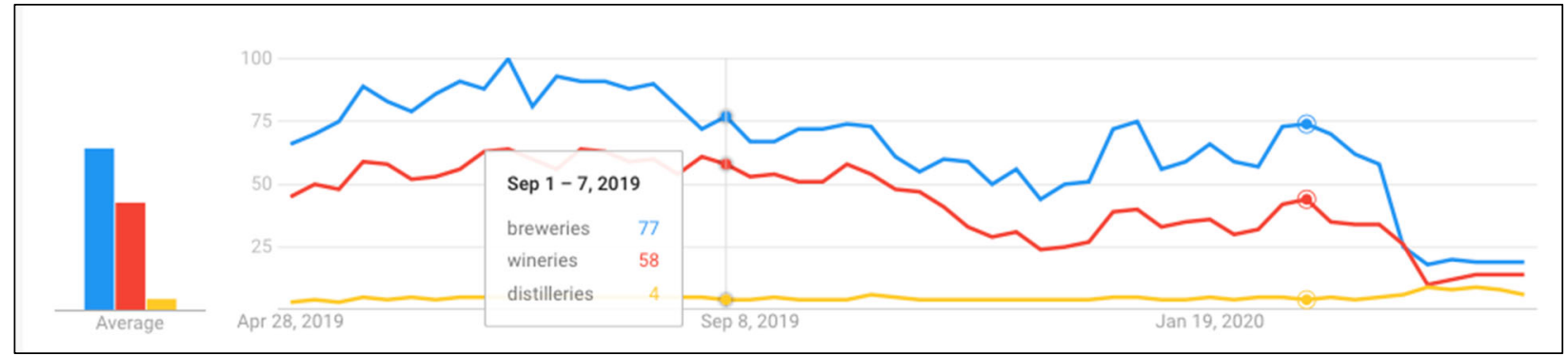

Source: Google Trends, April 27, 2020; the geography of search is the U.S.; circles to the right show week of February 16-22, 2020 as period of decline.

${ }^{4}$ The average consumer likely does not know the name of their local brewery or winery, and may just be looking for generic terms to find an alternative to what they know (which was perhaps their closest go-to state store). 
Figure 5b. Search Intensity for Breweries, Wineries, and Distilleries with Liquor Stores
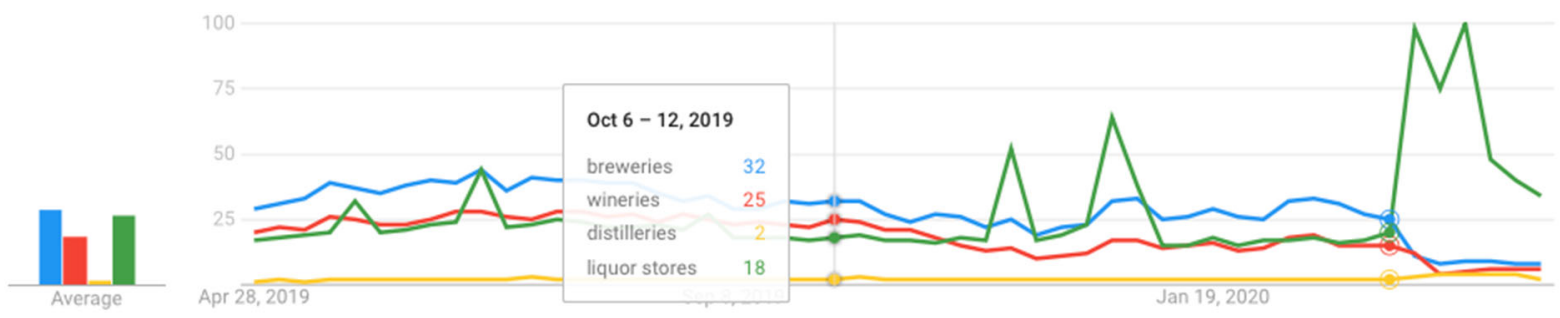

Source: Google Trends, April 27, 2020; the geography of search is the U.S.; circles to the right show week of March 8-14, 2020 as period of increase for liquor store searches, such as the decline for breweries/wineries accelerates (suggesting substitute stores/goods).

For brewery searches, the greatest interest was in the northern New England states, while for wineries it was along the western coastal U.S. and, somewhat surprisingly, Kentucky. Many breweries are now having to deal with kegs that will turn stale within a couple of months, amounting to losses estimated at US\$1 billion (Chaudhuri, 2020). This has sparked innovative collaborations among brewers and distillers across the country, who are rescuing stale beer by distilling the kegs for the production of whiskey and hand sanitizer (Japhe, 2020).

\section{Conclusion and Shortcomings}

Even though demand for local food has increased over the past decade, only a small number of Americans buy regularly from local food outlets, such as farm stands, farmers markets, and CSAs (Kolodinsky et al., 2020). It is likely that interest in local products and markets has increased because of consumer demand for convenient and safe access during this time of sheltering, where distant travel is restricted. It remains to be seen whether consumer interest in local will persist as restrictions loosen in the coming months, and how innovations in short supply chains during the peak of the pandemic will ultimately affect the long-term profitability of local foods systems (e.g., Ahearn, Liang, \& Goetz, 2018).

What we show in this commentary has shortcomings, including inherent noise in the data based on the search terms. Nevertheless, this relatively quick examination of Google searches shows how real-time data can be collected and interpreted to understand what is preoccupying consumers from week to week during a pandemic. More refined analyses could be carried out in the future, with rigorous hypothesis testing.

\section{References}

Ahearn, M. C., Liang, K., \& Goetz, S. J. (2018). Farm business financial performance in local foods value chains. Agricultural Finance Review, 78(4), 470-488. https://doi.org/10.1108/AFR-08-2017-0071

Arora, V. S., McKee, M., \& Stuckler, D. (2019). Google Trends: Opportunities and limitations in health and health policy research. Health Policy, 123(3), 338-341. https://doi.org/10.1016/j.healthpol.2019.01.001

Carneiro, H. A., \& Mylonakis, E. (2009). Google Trends: A web-based tool for real-time surveillance of disease outbreaks. Clinical Infectious Diseases, 49(10), 1557-1564. https://doi.org/10.1086/630200

Chaudhuri, S. (2020, April 24). A new problem is brewing in the beer industry: One million kegs are going stale. The Wall Street Journal. Retrieved from https://on.wsj.com/3bTMoQB

Distilled Spirits Council. (n.d.). Distilleries making hand sanitizer to fight COVID-19. Retrieved April 20, 2020, from the Distilled Spirits Council website: https://www.distilledspirits.org/distillers-responding-to-covid-19/distilleries-making-hand-sanitizer/ 
Ebrahimji, A. (2020, April 15). Pennsylvanians are driving out of state to buy liquor, so neighboring states are cracking down. CNN. Retrieved from https://cnn.it/35h9U7M

Ginsberg, J., Mohebbi, M. H., Patel, R. S., Brammer, L., Smolinski, M. S. \& Brilliant, L. (2009). Detecting influenza epidemics using search engine query data. Nature, 457, 1012-1014. https://doi.org/10.1038/nature07634

Japhe, B. (2020, April 27). Distilleries are turning stale beer into coronavirus whiskey. Bloomberg. Retrieved from https://bloom.bg/2yYNkV8

Kelleher, S. R. (2020, March 28 / Updated April 6). 45 U.S. states shut down and counting: State-by-state travel restrictions. Forbes. Retrieved from https://bit.ly/3bSLR1s

Kolodinsky, J., Sitaker, M., Chase, L., Smith, D., \& Wang, W. (2020). Food systems distuptions: Turning a threat into an opportunity for local food systems. Journal of Agriculture, Food Systems, and Community Development. Advance online publication. https://doi.org/10.5304/jafscd.2020.093.013

Kulish, N. (2020, April 8 / Updated May 6). 'Never seen anything like it': Cars line up for miles at food banks. The New York Times. Retrieved from https://nyti.ms/2WdeSy3

Mavragani, A., \& Ochoa, G. (2019). Google Trends in infodemiology and infoveillance: Methodology framework. JMIR Public Health and Surveillance, 5(2), e13439. https://doi.org/10.2196/13439

Mavragani, A., Ochoa, G., \& Tsagarakis, K. P. (2018). Assessing the methods, tools, and statistical approaches in Google Trends research: Systematic review. Journal of Medical Internet Research, 20(11), e270.

https://doi.org/10.2196/jmir.9366

Mervosh, S., Lu, D., \& Swales, V. (2020). See which states and cities have told residents to stay at home. The New York Times. Retrieved March 31, 2020, from https://nyti.ms/3bTlsjU

Nuti, S. V., Wayda, B., Ranasinghe, I., Wang, S., Dreyer, R. P., Chen, S. I., \& Murugiah, K. (2014). The use of Google Trends in health care research: A systematic review. PLOS ONE, 9(10), e109583. https://doi.org/10.1371/journal.pone.0109583

Schmidt, C., Tian, Z., Goetz, S., Bartley, B., Moyer, B., \& Rocker, S. (2020, April 1). Farms with direct to consumer sales in the Northeast region and COVID-19: Some early challenges and responses (NERCRD COVID-19 Issues Brief 2020-1). State College: Northeast Regional Center for Rural Development, Pennsylvania State University. Retrieved from https://aese.psu.edu/nercrd/publications/covid-19-issues-briefs/covid-19-and-farms-with-direct-toconsumer-sales

Trading Economics. (n.d.). United States initial jobless claims. Retrieved April 20 from https://bit.ly/2KPesZG

Whelan, A. (2020, March 17). As Pa. liquor stores close, advocates worry about risks of sudden alcohol withdrawal. The Pbiladelphia Inquirer. Retrieved from https://www.inquirer.com/health/coronavirus/pennsylvania-liquor-storesclosing-alcohol-dependence-addiction-20200317.html

Worstell, J. (2020). Ecological resilience of food systems in response to the COVID-19 crisis. Journal of Agriculture, Food Systems, and Community Development. Advance online publication. https://doi.org/10.5304/jafscd.2020.093.015 